\title{
Pluralism, Consensus and the Ambiguities of Multiculturalism
}

\author{
Dr. Marco Boschele
}

\author{
Yeditepe University Istanbul
}

\section{Doi:10.5901/ajis.2013.v2n9p38}

\begin{abstract}
Multiculturalism and the attempt to accommodate cultural diversity have been questioned from different fronts. On the one hand, political criticism, based on "fear" and "anxiety" about "others" combined with emphasis on national identity has characterised the political agenda in terms of security in Europe. On the other hand, philosophical criticism questioned concepts such as "identity politics", the "politics of recognition" and the "politics of difference" which aim to emphasise the struggle of minorities. This position points out that multiculturalism seems to promote extreme diversity at the expenses of consent, a necessary condition for governing. This has also exposed the general assumption that accommodating ethnic and religious minorities, in the light of plurality of values and interests, is central to liberal democracies thus uncovering the difficulty of achieving political consensus in increasing culturally diverse societies. Within this context, this work will first explore concepts such as "identity politics", the "politics of recognition" and the "politics of difference" in relation to the assumption that to achieve a consensus based on cultural difference may undermine civil consensus. Moreover, focus on identity and culture diverts from economic justice undermining multiracial class solidarity. Secondly, in order to determine the ambiguity of consensus and pluralism, this work will explore the work of John Rawls and Jean Françoise Lyotard. In their works, it is implied that modern societies are characterised by innumerable narratives and doctrines making them pluralistic. This conjecture is common in both thinkers, but for the former it is a positive result of the development of civil society where consensus is attainable, for the latter any form of consensus is to be avoided because can be a tool for political authority. This contradiction points out that a form of consensus is needed to achieve a politics of social and political cohesion within society but at the same time it warns about the danger of a dominant culture and the threat of exclusion.
\end{abstract}

\section{Introduction}

Multiculturalism and the attempt to accommodate cultural diversity have been questioned from different fronts. Tensions between minority groups and state authority in various European cities have characterised the first decade of the 21st Century ${ }^{1}$. Political criticism, based on "fear" and "anxiety" about "others" and on national identity and solidarity, has been the most challenging2. These issues have risen when economic conditions have been characterised by economic crisis fuelling alleged threats of security and national identity. In Europe, minorities in general and in particular Muslim minorities have come under increased monitoring and tougher border control. This has questioned the general assumption that accommodating ethnic and religious minorities in the light of plurality of values and interests, is central to liberal democracies thus exposing the difficulty of achieving political consensus in increasingly culturally diverse societies. In the philosophical sphere, multiculturalism in the forms of "identity politics", the "politics of recognition" and the "politics of difference"* which aim to emphasise the struggle of minority groups, have been questioned by different critiques.

\footnotetext{
12001 in Northern England, civil unrest in France in 2005, the "terrorist" events in the United States in 2001 in Spain in 2004 and in Britain 2005, and also the tensions for the building of mosques in Italy, France, Germany and Greece.

${ }^{2}$ In 2010 Angela Merkel the German Chancellor stated that multiculturalism had "utterly failed", arguing for a stronger acceptance of German cultural values and knowledge of the German language. Similarly, in 2011 Nicolas Sarkozy declared that there had been more concentration on the identity of immigrants rather than about the identity of the receiving country. Australia's former Prime Minister John Howard and former Spanish Prime Minister Jose Maria Aznar have also in recent months said multicultural policies have not successfully integrated immigrants. David Cameron Britain must adopt a policy of "muscular liberalism" to enforce the values of equality, law and freedom of speech across all parts of society.

http://www.telegraph.co.uk/news/worldnews/europe/france/8317497/Nicolas-Sarkozy-declares-multiculturalism-had-failed.html http://www.independent.co.uk/news/uk/politics/cameron-my-war-on-multiculturalism-2205074.html http://www.bbc.co.uk/blogs/thereporters/gavinhewitt/2010/10/failure_of_multiculturalism.html

* These concepts will be cited interchangeably.
} 
Some argues that we live in a world were cultures are not self-contained units but the world, due to technology, economy, trade, is more characterised by cosmopolitanism (Waldron 1995). Others argue that rights should be given only to individuals and not to groups. If the state gives rights to groups it fails to secure civility and individual rights (Kukathas 1995). Another criticism emphasises the politics of redistribution, seeking economic restructuring, over the politics of recognition where the key to equality is cultural and symbolic change (Fraser and Honneth 2003). The concern is that focus on identity and culture diverts from economic justice undermining multiracial class solidarity. These positions point out that multiculturalism seem to promote extreme pluralism at the expenses of consensus as a necessary condition for governing.

In these debates it is suggested that to achieve a consensus based on cultural difference may undermine civil consensus. This means that to embark on a policy of difference may undermine a politics of social and political cohesion within society. Within this context, this work will first explore concepts such as "identity politics", the "politics of recognition" and the "politics of difference" in relation to the assumption that to achieve a consensus based on cultural difference may undermine civil consensus. Moreover, focus on identity and culture diverts from economic justice undermining multiracial class solidarity. Secondly, in order to expose the ambiguity of consensus and pluralism, this work will explore the work of John Rawls and Jean Françoise Lyotard. In their works, it is implied that modern societies are characterised by innumerable narratives and doctrines making them pluralistic. This conjecture is common in both thinkers, but for the former it is a positive result of the development of civil society where consensus is attainable, for the latter any form of consensus is to be avoided because can be a tool for political authority.

\section{Liberalism and multiculturalism}

Concepts, such "identity politics", the "politics of recognition" and the "politics of difference" are closely related to the notion of multiculturalism and refer to theories and policies which acknowledge certain injustices suffered by member of social groups. ${ }^{3}$ Their main purpose can be seen as an implicit and an explicit critique of liberalism ${ }^{4}$ and of the norm of equality which makes similar treatment as an ideal, thus, the shift is not only from the protection of individual liberty but also from the Enlightenment ideals of human equality and similarity. The criticism of such ideals is based on the belief that in cultural diverse societies individuals may be required to be treated differently by allowing exceptions or regulating activity which undermine or promote cultural minorities. In some cases state neutrality covers up ways in which the state favours majorities in terms of culture, nation or, language. This means the recognition of social power which does not rest in the control of the state but that disadvantages minorities. In this way, multiculturalism as such, expands the understanding of how power functions and how it prevents the state to develop justice in culturally diverse societies.

The philosophical literature which reinforces the critique of liberalism then is based on the nature and origin of identities subjected to discrimination. This means that identity, as a member of an ethnic minority, places one in an unfair position in relation to cultural dominance, discrimination, violence, and marginalization. Moreover, multiculturalism considers 'oppression' and from there it proposes the transformation of set interpretations of group membership. Instead of accepting the dogmatism of the dominant culture there is the conscious transformation of sense of the self and community.

The philosophical discussion of the concept of identity raises theoretical questions 'about the sense of the self' and about 'the nature of subjectivity and the self' (Taylor 1989). Taylor maintains that the 'modern identity' has the capacity for 'authenticity' which means the ability of being true to oneself. The politics of difference has taken the concept of authenticity to describe ways of living which are related to identities of marginalised social groups. The difference with previous approaches is the demand for recognition on the basis on which recognition had previously been denied since the demand is not about inclusion in a universal understanding of humankind but respect for the difference of someone

\footnotetext{
3 These political movements in America were feminist, Black Civil Rights, American Indian movements. In Europe such movements were related to the claims of linguistic minorities.

${ }^{4}$ Although liberalism itself rose as a philosophy in response to issues of diversity and particularly to the religious wars of 16th and 17th century in Europe, originating the division between church and state. Will Kymlicka identifies three main stages of the history of debate about minority rights. In the first stage, minority rights within the communitarian debate and rejection of individualism in favour of collectivism. The second stage is characterised by the belief that minority rights could be defended within the liberal framework. A third stage, minority rights are seen as a response to nation-building. This means that the liberal state has not been neutral in relation to cultural issues but it has been engaged in nation-building. In this case minority rights are thought to be necessary in specific historical and political contexts (Laden and Owen 2007).
} 
(Taiaiake Alfred 1999). Important to multiculturalism is that individuals share the same political experience. Individual perception of their own interests may be distorted and may be freed of their misconceptions by group based transformations. For example, the theoretical meaning of a particular experience may be different from the meaning attributed by the subject; such dislocations are understood under the concept of false consciousness.

Problems with these aspects of multiculturalism focus on the fact that experience is never available prior to interpretation but it require a theoretical framework to give meaning (Song 2010). This means that belonging to a certain group makes a person qualified to that political decision based on what we are, but it can be objected that political decisions should be informed by values and principles rather than identities. Also, if experience is the origin of politics, political perspectives gain legitimacy by virtue of their articulation by subjects of particular experiences. This however, prevents the possibility of critique of these perspectives by those who do not share the experience which in turns impedes political consensus and coalition building.

Furthermore, liberal Universalists hold that issues raised by cultural diversity do not require the exclusion of universal political theories and universal liberal principles. For instance, Brian Berry (2007) maintains liberal universalism on the basis that cultural diversity should be ignored by political theory and regarded as personal tastes. Simon Caney claims that political claims made by cultural minorities can be accommodated within universal political theory. Caney adopts a universalistic approach that any less robust defence of rights is incoherent. Iris Young (2007) and Charles Mills (2007) argue that focus on the politics of difference 'obscured structural inequality's.

Such critiques of multiculturalism led thinkers to regard it as essentialist. Firstly, the understanding of the subject gives priority to identity and second, generalizations made about particular social groups in the context of identity politics make cultures separately closed and internally uniform, dictating the self-understanding that its members should have. In these debates it is also possible to recognize that to achieve a consensus based on cultural difference may undermine civil consensus. This means that to take on a policy of difference may undermine a politics of social and political cohesion within society.

\section{Consensus and plurality in Rawls and Lyotard.}

In the light of these considerations, this section considers the positions of John Rawls and Françoise Lyotard on consensus in plural societies. The publication of John Rawls' A Theory of Justice diverted the focus on migration and cultural diversity (Owen 2007:5) and Lyotard's commitment has often being employed to expose the insurmountable barrier of difference. In their works, it is implied that modern societies are characterised by innumerable narratives and doctrines making them pluralistic. This assumption is common in both thinkers, but for the former it is a positive factor as the result of the development of civil society where consensus is attainable, for the latter, any form of consensus is to be avoided because can be a tool for cultural and political dominance. Rawls develops a conception of agreement which seeks to overcome fundamental differences of the notion of the 'good' since justice is only attainable when an established understanding of the political good is agreed by individuals within a polity. This agreement which takes the form of a contract requires the autonomy of individuals who can determine interests and ends according to their political needs. On the other hand, Lyotard shows the commitment to avoid absolute moral principles. In fact, Lyotard questions the role of language and argue that the distinct nature of language games characterises the function of language and therefore justice becomes the recognition of differences rather than the attempt to unify them. The original position exposed in Rawls and the notion of obligation in Lyotard, form the basis from which prescriptions are possible to be made and also provide the possible point of contrast since Lyotard, contrary to Rawls, argues that 'there is no community of ethical phrases.

In A Theory of Justice, the Kantian concept of autonomy is central to the formulation of Rawls' concept of justice since it allows the individual to be an autonomous chooser of moral ends. From the outset Rawls relies on the notion that the individual acts autonomously because the principles for her/his actions are chosen as the characteristics of a 'free rational beings'. Rawls needs this starting point to ensure that individuals in the 'original position' would not follow a 'plan that views the sense of justice as but one desire to be weighed against others' (Rawls 1972:86). In constructing these presuppositions Rawls wants to eliminate conflicts that exist within individuals by arguing that it would be 'reasonable' for individuals to recognise justice as the first and fundamental value and that the principles of justice are within the capability

\footnotetext{
${ }^{5}$ Young's politics of 'positional difference' is concerned with groups which are formed as a result of social hierarchies, like the social
} division of labour, the power to decide institutional actions and the construction of social norms. 
of rational minds. Here Rawls shows that the individual is prior to society and that the latter does not influence the choices about justice.

In Justice as Fairness: A Restatement (2001)6 Rawls' employs the 'original position' as an hypothetical space, which is not a temporal nor a body of people but is delineated by reasoning agents operating within 'modelled constraints' and 'led by the same judgment as to which principles to adopt'. From this deduction, the original position therefore, serves mainly two purposes for assuring that justice can provide a 'fair argument'. The first is to grant the 'fair conditions' where 'free and equal persons' can find an agreement in order to co-operate fairly. The second works as a restrictive device since, through representation, it puts forward certain principles of justice and rejects others based on 'acceptable restrictions'. Rawls points out that the original position, by allowing different assumptions, locates the implications of other concepts of justice so they can be scrutinised with the intent to put forward the basis for a 'political conception of justice'. Constrains which delineate the original position and constitute a political body are governed by 'the same judgment as to which principles to adopt'. To achieve this preliminary condition Rawls formulates another fundamental device, 'the veil of ignorance'. This concept ensures that parties are guided by the same 'body of general facts' and by the same judgment in order to reach unanimous agreement. This is achieved by limiting the parties to the same understandings of social theory and under the circumstances of justice which make a liberal democracy possible.

Behind the veil of ignorance parties would not know their place in society in terms of abilities or intelligence, class position and social status, race, religion, gender, political believes, so that they would not recognise different conceptions of the good ('justice objective and subjective' and 'making a constitutional democracy possible obtain') (Sterba 2003:108). The veil of ignorance overcomes these fundamental differences by offering advantages to all the competing parties and allowing them the same opportunity to choose principles of justice. This will place them in a symmetrical position and following the principle of equity, equality would also be symmetric and therefore in correct proportion. Crucial for Rawls' theory is that parties are rational so that they can position their ends consistently and can also adopt the most effective means to advance those ends. Here the veil of ignorance helps to decide which grounds can be adopted in the original position, since parties do not have any cognition of concepts of the good and their social position. To facilitate this decision, Rawls maintains that there is the need to introduce the idea of 'primary goods' which are things that people need as 'citizens' and not as 'human beings' or in other words the grounds for justice are political rather than moral to specify the 'two principles of justice'.

The principles of justice are set up to regulate social and economic inequalities and to ensure basic rights and liberties. The first principle states that liberties are the same for every one and the second that social and economic inequalities have to satisfy certain conditions. This requires institutions and implications for rights and duties for distributive justice to work in a way which allows equal access to all in offices and expectation will determine the function of these institutions. The expectations of any position depends on the expectation of others and ultimately on the established rights and duties which make constitutional democracy possible to obtain.

This brief account of Rawls' seeks to justify inequalities within liberal democracies as long as there is enough to improve the worse off in society. Rawls' account also collocates him within the pragmatic tradition since his account on justice is not about how the 'good' should be determined but how individuals within a democratic society have the possibility to access the opportunities in terms of economic status or position in public office. Nevertheless, this is only possible if differences which constitute the social order are ignored, as in a hypothetical state of nature, where what can be regarded as universal is the rationality of individuals and their determination to seek justice in order to preserve the existing status quo. It can also be argued that with increasing economic interrelations together with growing relations in the field of information, political judgment has to account for more than maintaining the status quo of the better off, but also for the repercussion that such implications have on less equipped communities. It is perhaps in this context that a different reading may help to reflect a bit further on its meaning whose legitimacy rest on the liberal tradition and institutions which constitute liberal democracies.

In fact, for Lyotard this understanding of justice does not take into account 'differences' which exist in society and therefore, any attempt to ignore them would be 'unjust'. Instead, justice should consider the incommensurability of differences and precisely his 'pagan' philosophy is characterised by a radical concern for pluralism or as he puts it, the recognition for the 'multiplicity of language games' as opposed to universality (Lyotard 1979).

\footnotetext{
${ }^{6}$ In this work 'the principles of justice' are justified by 'two fundamental comparisons'. In A Theory of Justice the principles of justice
} relied on the 'maximin strategy'. 
Lyotard's 'reformulation' rests on the critique of the modern understanding of justice which, following Plato, requires a stable structure of judgment. He argues that traditionally, the distribution of goods in society is just, if it conforms to the idea of justice as an 'essence' stated by the 'philosopher who can determine the meaning' of what is just. Justice, therefore, in a Platonic sense, 'implies the representation of something that is absent', something that lacks in society and must be restored. Justice also requires a statement which is 'true' and which 'subordinates the social practice of justice to itself'. This is characteristic of the Western political tradition which can be also seen in Marxism since 'a correct analysis' can tell us the distribution of goods and provide legitimacy for a 'communist distribution of goods'.

Justice in the liberal and Marxist tradition is, therefore, constituted of two assumptions. That there is a theoretical procedure to determine what is lacking in society in order to be good and that there is a set of discourses which prescribes it. For Lyotard the problem is that these two notions differ since the 'prescriptive' is derived from the 'descriptive' (Lyotard 1996:19-22). Following Aristotle, Lyotard argues that prescriptive and descriptive statements do not belong to the same class. On the contrary, there is incommensurability between the two, since they are not proportional and therefore the 'just' cannot be derived from the 'true'. Similarly in political thought justifications of just action, in terms of distribution, show limitations because there cannot be justifications in a denotative statement. Plato maintained that if one has a just view of 'being' it can be translated into a true understanding of social organisation and also of just distribution. But for Lyotard a prescription can be just only if the addressee can put itself in the position of the sender so that the 'command' can be legitimated (Lyotard:1996:23; 1988:108). The passage from the true to the just shows, in Lyotard's view, a problem which characterize the role of intellectuals in Western tradition and which also shows the difficulty to legitimise political discourse and ultimately justice. This difficulty leads to the assumption that the question of justice cannot be resolved by a 'just' constitution and that we cannot envisage a model of a just society. Justice in this sense becomes the refusal of any criteria that entails prescriptions and consequently it implies that there is no grand narrative which can capture the complexity of events and provide the basis for judgment to ground political and ethical decisions in all situations.

The other concern for Lyotard, which reinforces his claims against criteria in favour of pluralism, is the fact that justice in the modern sense gives priority to the moral autonomy of the subject. Lyotard argues that this attitude, particular to modern discourse, shows another problematic because the subject is at the same time 'the sender and receiver' of the law which constitute the moral requirements for justice. This formulation of ethical judgments is mainly characteristic of Kant's Critique of Pure Reason in which the notion of the 'categorical imperative' provides the individual with the faculty to formulate autonomous moral judgments.

This interpretation is characterized by a determination to explore the question of legitimacy within political discourse and an interest in language as the vehicle to represent such legitimacy. It is important here to note that for Lyotard any formulation of principles which may determine what justice is cannot derive from discourses which disallow other discourses to be part of the political arena. This entails that there cannot be bridges, in the form of 'metanarratives', between prescriptive and descriptive genres because it would be totalising different aspects of phrases as shown in the critique of Plato or Marx. It is this incommensurability of genres which Lyotard wants to preserve from a discourse which is totalising and justice in this way takes the form of a commitment to acknowledge the boundaries within genres and to preserve the integrity of genres that are wronged by the conflict with other genres.

\section{Conclusion}

The setback between the inclusive character of liberalism and the plural aspect multiculturalism exposed the limit of the liberal state to include ethnic and religious minorities as well as the boundaries of multicultural policies to address issues of diversity and integration. At theoretical and political level, the debate has been between cultural and civic recognition and at the same time, a recurrence of universalism and national identity in a time when we witness a decline of the nation as cultural entity. The politics of multiculturalism seeks to promote cultural diversity and to prevent ethnic and religious discrimination, and similarly, pluralism and tolerance have been the values of liberalism. The development of the politics of difference was nevertheless, a rejection of the liberal values of equality, characteristic of the Enlightenment this time regarded as the perpetrator of totalitarianism.

It is within this debate that the paradox of consensus and pluralism arises within the theories of multiculturalism. Objections are about the boundaries that multiculturalism delineates within different cultural groups and by the notion of political experience based on identity rather than values. This is precisely what Rawls elaborates in his conception of distributive justice. He develops a conception of the good by eliminating all the differences that exist in the pluralistic society by appealing to the classic liberal concept of individual autonomy and ethical symmetry between individuals. This is in a way the continuation of the core values of the Enlightenment project and at the same time, the effort to create the 
condition where political consensus can be achieved. To juxtapose this liberal approach to tackle the experience of pluralism, the multicultural approach in its extreme representation can be interpreted in the works of Lyotard. He, contrary to what Rawls elaborates, seeks to maintain the pluralistic character of societies, because the danger of a totalitarian politics is precisely the attainment of consensus. For Lyotard, justice is indeed the acknowledgment of differences and if understood as a concept which should not advantage one group over another, it should not be the interpretation of a particular community especially if the claims for justice are validated by the function of knowledge as a legitimising tool to provide universal recognition. This contradiction points out that a form of consensus is needed to achieve a politics of social and political cohesion within society but at the same time it warns about the danger of a dominant culture and the threat of exclusion. This ambiguity can be understood between consensus and plurality: the search for a new metanarrative in a modern sense and at the same time the awareness of the danger of absolutism as a balance between the modern enthusiasm and nihilism.

\section{References:}

Alfred, T., (1999) Peace, Power, Righteousness : an Indigenous manifesto, Oxford University Press Canada.

Barry, B.,( 2001), Culture and Equality: An Egalitarian Critique of Multiculturalism. Cambridge, MA: Harvard.

Fraser, N., and A. Honneth, 2003, Redistribution or Recognition? A Political-philosophical Exchange, London: Verso.

Kukathas, C., 1995, "Are There Any Cultural Rights?" Political Theory.

Kymlicka, W., "The New Debate over Minority Rights" in Multiculturalism and Political theory (2007) Ed. By Laden, A. S., Owen, D. Cambridge University Press.

Lyotard, J.F (1979) The Postmodern Condition: A Report on Knowledge Trans. Geoff Bonnington and Brian Massumi. Manchester. Manchester University Press.

Lyotard, J.F \& Thebaud, J.L (1996) Just Gaming (4th edit.). Trans. Brian Massumi in 'Theory and History of Literature' Vol. 20 Trans. Wlad Godzich \& Samuel Weber Minnesota University Press.

Mills, W.C., (2007) "Multiculturalism as/and/or anti-racism" in Multiculturalism and Political theory (2007) Ed. By Laden, A. S., Owen, D. Cambridge University Press.

Owen, D. and Laden, A. S., Ed. (2007) Multiculturalism and Political theory. Cambridge University Press.

Rawls, J (1972) A Theory of Justice Oxford. Clarendon Press.

Rawls, J., (2001) Justice as Fairness: A Restatement Cambridge, Massachusetts: Belknap Press

Sterba, P (2002) Justice: Alternative Political Perspectives (4th ed.) Wandsworth. Thompson.

Song, Sarah, (2010), "Multiculturalism", The Stanford Encyclopedia of Philosophy (Winter 2010 Edition), Edward N. Zalta (ed.).

Taylor, C., (1989) Sources of the Self: The Making of Modern Identity Harvard University Press.

Young, I., (2007) "Structural Injustice and the Politics of Difference" in Multiculturalism and Political theory (2007) Ed. By Laden, A. S., Owen, D. Cambridge University Press.

Waldron, J., (1995), "Minority Cultures and the Cosmopolitan Alternative," in The Rights of Minority Cultures, Oxford: Oxford University Press. 